\title{
THE SERUM POLYSACCHARIDES IN DIABETIC PATIENTS WITH AND WITHOUT DEGENERATIVE VASCULAR DISEASE
}

\author{
BY JAMES BERKMAN, HAROLD RIFKIN, AND GEORGE ROSS \\ (From the Laboratory and Medical Divisions, Montefiore Hospital, New York, N. Y.)
}

(Submitted for publication October 17, 1952; accepted January 21, 1953)

Complex carbohydrate substances have been demonstrated histologically in hyaline material present in the glomerular and retinal capillary lesions which develop in diabetic patients. There has been increasing speculation that the source of this material might be polysaccharides present in abnormal amounts in the blood of such individuals (1-3). Hitherto, however, the glycoproteins in the sera of diabetic patients have not been investigated systematically. A few observations suggest that abnormal concentrations of these substances occur in the serum of such patients (4), but others indicate that they are within the normal range $(5,6)$. Insufficient additional information is presented in these studies to allow correlation of the values observed with the absence, or presence, and extent of vascular complications.

This report is based on a study of certain polysaccharide components in the sera of diabetic patients with and without clinically detectable degenerative vascular disease. The results indicate that significant increases in the serum concentrations of some of the substances measured do occur in individuals with this complication. The possible significance of these observations is discussed.

\section{MATERIAL}

Sera were obtained from 91 patients from the wards and clinics of Montefiore Hospital, other hospitals, or from the office practice of private physicians. The subjects were free from demonstrable diseases other than diabetes, such as cancer, acute and chronic infections, and acute myocardial infarction, which are known to influence the concentration of polysaccharides in the serum (5-14). Sixty-six patients had diabetes mellitus. This group was divided further into three categories, depending on the existence and extent of associated degenerative vascular complications. Since one subgroup of diabetic patients had impairment of renal function, which may affect the serum polysaccharide levels, 10 non-diabetic individuals with renal disease were included to evaluate the effects of renal insufficiency per se. Fifteen subjects who had neither diabetes nor renal disease formed a control group.

\section{Group I. Non-diabetic controls}

This group consisted of 15 individuals who were seen for periodic examinations and found to be in good health. Their ages ranged from 28 to 88 years. Diabetes and renal disease were excluded by appropriate studies.

\section{Group II. Patients with diabetes mellitus}

This group was made up of 66 patients. Depending on the existence and extent of degenerative vascular complications, they were divided into three subgroups:

\section{A. Uncomplicated}

Fourteen patients, varying in age from 36 to 73 years, formed this class. Diabetes was known to have existed for 2 to 13 years with an average of about seven years. Four individuals did not require insulin. The other 10 patients required between 10 to 30 units of insulin per day. Hypertension, proteinuria, renal insufficiency, retinopathy, neuropathy, coronary artery and peripheral vascular disease were excluded by appropriate clinical, laboratory and X-ray examinations.

B. Complicated: degenerative vascular disease without hypertension, proteinuria, or renal insufficiency

There were 18 patients in this category. Their ages ranged from 27 to 83 years. The known duration of diabetes was 4 to 20 years, with an average of about 11 years. The insulin requirement of these patients varied from 0 to 120 units per day. Individuals in this category had one or several degenerative vascular complications which included retinopathy, neuropathy, occlusive coronary artery and peripheral vascular disease.

C. Complicated: degenerative vascular disease with hypertension, proteinuria, and renal insufficiency

The 34 patients in this group varied in age from 28 to 83 years, and were known to have had diabetes for 10 years or more, except for one individual in whom the known duration of this disease was eight years. These patients required 0 to 110 units of insulin daily. Individuals in this category had degenerative vascular changes similar to those found in the preceding category (Group IIB). However, in addition, hypertension and proteinuria, and, in most cases, renal insufficiency existed. A fully developed Kimmelstiel-Wilson's syndrome (15) was demonstrated in 14 individuals. The urinary sediments of the remaining 20 patients were not specifically examined for doubly refractile lipoids. Therefore, whether these 20 patients had hypertensive renal vascular disease 
(nephrosclerosis) alone, or in association with diabetic glomerulosclerosis, was not settled.

\section{Group III. Non-diabetic patients with renal disease}

There were 10 patients in this group. Two individuals had acute diffuse glomerulonephritis and three had chronic glomerulonephritis. There were three patients with hypertensive renal vascular disease and renal insufficiency, one with chronic pyelonephritis, and one with renal amyloidosis.

\section{METHODS}

Twenty to $30 \mathrm{ml}$. of blood were drawn by venipuncture from subjects in the post-absorptive state and placed in a refrigerator. Within four to six hours, the sera were separated and again stored in a refrigerator until they were analyzed on the following day. Samples containing even small amounts of hemoglobin were discarded.

Total non-glucosamine polysaccharides bound to serum protein were measured by the anthrone method of Graff and his associates (16). Serum glucosamine was determined by the procedure of West and Clarke (6). Mucoprotein was isolated from the serum and analyzed for protein by estimating the tyrosine content using Folin's reagent according to the method of Winzler and his associates (17). The non-glucosamine polysaccharides in the mucoprotein fraction of the serum were determined by Graff's method (16). Analyses were performed in duplicate. The differences between duplicate determinations were 3 per cent or less for the non-glucosamine polysaccharides bound to serum protein, 4 per cent or less for serum glucosamine, and 5 per cent or less for the carbohydrate and protein components of the mucoprotein. The sensitivity and specificity of the isolation procedures and colorimetric reactions on which these measurements depend are poorly understood, but the results are repro- ducible with reasonable accuracy. Control values which we obtained are in good agreement with those previously reported by other investigators.

Fasting blood sugars were determined simultaneously on separate blood samples by the Somogyi method.

\section{RESULTS}

The values obtained for the serum polysaccharide substances measured in the various groups are summarized in Table I, and represented graphically in Figures 1, 2 and 3.

\section{Total non-glucosamine polysaccharides bound to serum protein (Figure 1)}

Values in the non-diabetic control group (Group I) ranged from 119 to $160 \mathrm{mg}$. per cent with a mean of $146 \pm 11.2 \mathrm{mg}$. per cent. The levels in uncomplicated diabetic patients (Group IIA) remained in the normal range. In contrast, distinct elevations of this component were found in the complicated diabetic groups (Group IIB and IIC), and in non-diabetic patients with renal disease (Group III).

\section{Serum glucosamine (Figure 2)}

The range in the non-diabetic control group was from 84 to $116 \mathrm{mg}$. per cent, with a mean value of $97 \pm 8.3 \mathrm{mg}$. per cent. Comparable values were obtained in the uncomplicated diabetic group. Again, significantly higher levels were obtained in

TABLE I

Serum concentrations of polysaccharide substances measured in the groups of patients studied

\begin{tabular}{|c|c|c|c|c|c|c|c|c|c|c|c|c|c|}
\hline \multirow{3}{*}{ Group } & \multirow{3}{*}{$\begin{array}{l}\text { Number } \\
\text { of cases }\end{array}$} & \multirow{2}{*}{\multicolumn{3}{|c|}{$\begin{array}{c}\text { Total non-glucosamine } \\
\text { polysaccharides bound } \\
\text { to protein } \\
\text { mg. per cent }\end{array}$}} & \multirow{2}{*}{\multicolumn{3}{|c|}{$\begin{array}{l}\text { Glucosamine } \\
\text { mg. per cent }\end{array}$}} & \multicolumn{6}{|c|}{ Mucoprotein } \\
\hline & & & & & & & & \multicolumn{3}{|c|}{$\begin{array}{l}\text { Non-glucosamine } \\
\text { polysaccharides } \\
\text { mg. per cent }\end{array}$} & \multicolumn{3}{|c|}{ 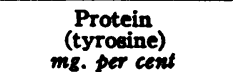 } \\
\hline & & Mean & S.D.* & S.E.t & Mean & S.D.* & S.E.t & Mean & S.D.* & S.E.t & Mean & S.D.* & S.E.t \\
\hline $\begin{array}{l}\text { I Non-diabetic } \\
\text { controls }\end{array}$ & 15 & 146 & 11.2 & 2.9 & 97 & 8.3 & 2.1 & 10.5 & 2.8 & 0.7 & 3.7 & 0.8 & $\overline{0.2}$ \\
\hline II Diabetic & & & & & & & & & & & & & \\
\hline $\begin{array}{l}\text { A. Uncomplicated } \\
\text { B. Complicated- } \\
\text { without renal } \\
\text { involvement }\end{array}$ & $\begin{array}{l}14 \\
18\end{array}$ & $\begin{array}{l}145 \\
184\end{array}$ & $\begin{array}{l}15.8 \\
21.5\end{array}$ & $\begin{array}{l}4.2 \\
5.1\end{array}$ & $\begin{array}{l}112 \\
145\end{array}$ & $\begin{array}{l}10.0 \\
15.1\end{array}$ & $\begin{array}{l}2.7 \\
3.6\end{array}$ & $\begin{array}{r}9.9 \\
12.3\end{array}$ & $\begin{array}{l}2.6 \\
4.3\end{array}$ & $\begin{array}{l}0.7 \\
1.0\end{array}$ & $\begin{array}{l}3.4 \\
4.1\end{array}$ & $\begin{array}{l}0.9 \\
1.3\end{array}$ & $\begin{array}{l}0.2 \\
0.3\end{array}$ \\
\hline $\begin{array}{l}\text { C. Complicated- } \\
\text { with renal } \\
\text { involvement }\end{array}$ & 34 & 193 & 26.3 & 3.5 & 153 & 20.2 & 4.5 & 18.3 & 9.9 & 1.7 & 5.3 & 2.0 & 0.3 \\
\hline $\begin{array}{l}\text { III Non-diabetic with } \\
\text { renal disease }\end{array}$ & 10 & 228 & 51.3 & 16.2 & 155 & 28.1 & 8.9 & 29.3 & 9.7 & 3.1 & 9.7 & 6.0 & 1.9 \\
\hline
\end{tabular}

* Standard Deviation.

† Standard Error of the Mean. 
Total Polysoccharides, mo/100 ml Serum

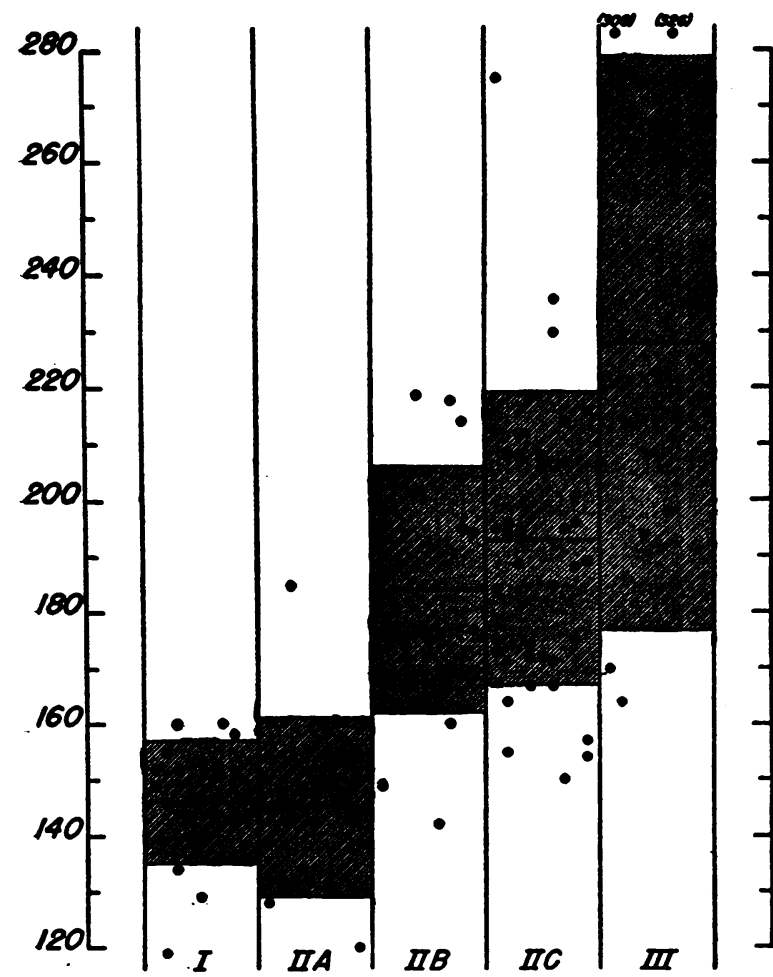

Fig. 1. The Total Non-glucosamine Polysaccharides Bound to Serum Protein among Patients in the Non-piabetic Control Group (I), Uncomplicated Diabetic Patients (IIA), Complicated Diabetic Patients without Renal Involvement (IIB) and Complicated Diabetic Patents with Renal Involvement (IIC)

III designates non-diabetic patients with renal disease. The dashed horizontal lines represent the mean in each group. The shaded area encloses the mean \pm S.D.

the complicated diabetic groups, and in nondiabetic patients with renal disease. As with the total non-glucosamine serum polysaccharides bound to serum protein, there was no significant difference between the concentrations observed in the complicated diabetic group with proteinuria, renal insufficiency and hypertension (Group IIC), and the complicated diabetic group without these findings (Group IIB). The average increases above normal levels were of a comparable order of magnitude in Groups IIB, IIC, and III.

\section{Serum mucoprotein (Figure 3)}

In the non-diabetic control group, the protein (tyrosine) content of the serum mucoprotein varied from 2.2 to $5.3 \mathrm{mg}$. per cent with a mean of
$3.7 \pm 0.8 \mathrm{mg}$. per cent. The non-glucosamine polysaccharide content was 6.1 to $14.0 \mathrm{mg}$. per cent with a mean value of $10.5 \pm 2.8 \mathrm{mg}$. per cent. In the uncomplicated diabetic group and, with one exception, among the complicated diabetic patients without renal disease, these values were in the normal range. Greater variations were encountered in the complicated diabetic patients with renal involvement and in non-diabetic patients with kidney disease. In some diabetic and nondiabetic patients with renal involvement, the levels of protein (tyrosine) and polysaccharide remained within normal limits; in others they were distinctly elevated. In the complicated diabetic patients without renal disease (Group IIB) the proportion of protein to carbohydrate was fairly constant and similar to that in Groups I and IIA. However, in diabetic (Group IIC) and non-diabetic (Group III) patients with renal disease, a consistent relationship was not noted. The concentration of the protein (tyrosine) component was abnormally elevated in individual cases, but it remained rela-

Ghucosamine, mg/100 $\mathrm{ml}$ serum

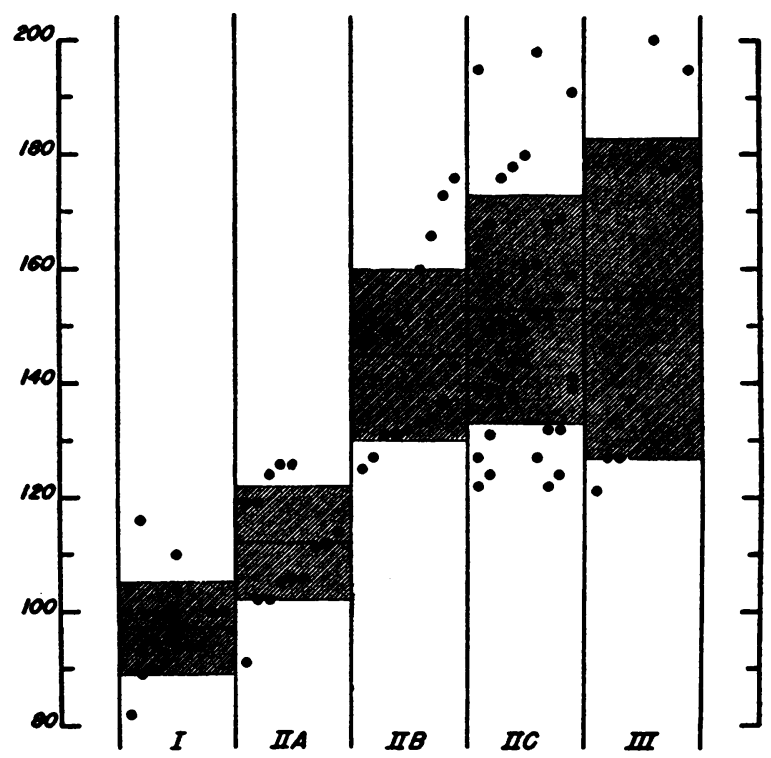

Fig. 2. Serum Glucosamine Content among Patients in the Non-Diabetic Control Group (I), Uncomplicated Diabetic Patients (IIA), Complicated Diabetic Patients without Renal Involvement (IIB), and Complicated Diabetic Patients with Renal INVOLVEMENT (IIC).

III denotes non-diabetic patients with renal disease. The dashed horizontal lines represent the mean in each group. The shaded area encloses the mean \pm S.D. 


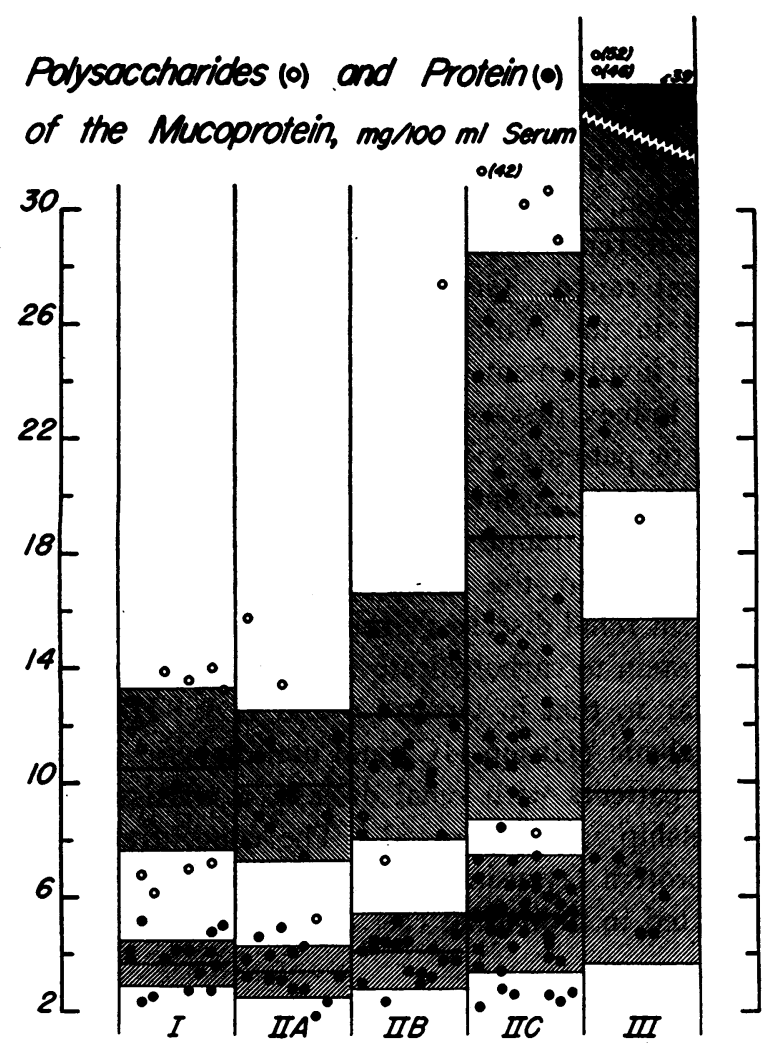

Fig. 3. The Non-glucosamine Polysaccharides (Open Circles) and Protein (Tyrosine) Content (Solid Circles) of the Serum Mucoprotein among Patrents in the Non-diabetic Control Group (I), Uncomplicated Diabetic Patients (IIA), Complicated Diabetic Patients without Renal Involvement (IIB), and Complicated Diabetic Patients with Renal DisEASE (IIC)

III designates non-diabetic patients with renal disease. The dashed horizontal lines represent the mean in each group. The mean \pm S.D. is enclosed in the shaded area.

tively more constant than the carbohydrate levels which fluctuated widely.

\section{DISCUSSION}

Relatively little is known as yet of the chemical structure, function, and metabolism of the polysaccharides in the serum of normal individuals (18). The significance of modifications of their composition and concentration which have been noted in patients with a wide variety of diseases is correspondingly obscure. One factor common to the pathologic conditions in which such changes have been observed is tissue injury. Accordingly, elevation of the serum polysaccharide concentra- tion is considered to be a non-specific index of destruction (7), or of proliferation and repair of tissue (5), perhaps reflecting the release into the circulation of substances derived from complex tissue carbohydrates. Experiments in which elevations of serum polysaccharides have been produced in animals by various types of tissue damage (19-22) lend some support to this concept.

Our results reveal that increased levels of certain polysaccharide substances in the sera of diabetic patients are associated with the existence of degenerative vascular complications, rather than with the primary metabolic defect in diabetes mellitus. Changes in the subintimal mucopolysaccharide ground substance have been implicated in the pathogenesis of arteriosclerosis (23, 24). One characteristic feature of the earliest sclerotic lesion in coronary arteries is a local increase in subendothelial mucoid ground substance (25). Our results may simply reflect such degenerative alterations widespread in blood vessels, and other structures. They do not exclude the possibility of a relationship of these increased circulating polysaccharides in such patients to the eventual development of specific glomerular and retinal capillary deposits of hyaline material. Because the diabetic patients in whom we observed abnormal serum polysaccharide concentrations already had well established degenerative vascular alterations, further data are required for clarification of these points. Serial observations are needed in the course of the development and progression of arteriosclerosis in diabetic as well as in non-diabetic individuals.

The changes in serum polysaccharide components in patients with kidney disease may represent the consequences of renal functional abnormalities, the effect of coexistent tissue alterations, or varying combinations of both these factors. In diabetic patients, the mean values for non-glucosamine polysaccharides of the serum protein, and for the serum glycosamine are elevated to comparable degree, and irrespective of the existence of abnormalities of renal function as evaluated by conventional clinical and laboratory methods. Combinations of extensive systemic vascular disease and renal dysfunction may account for the extreme increases in the values observed in individual patients. This possibility is further suggested by a progressive elevation of 
polysaccharide substances which we have found in the sera of a few patients with diabetic glomerulosclerosis, concomitant with increasing proteinuria, following the administration of corticotropin (26).

In none of the groups did we note a consistent interrelationship of the concentrations of the serum polysaccharide components measured. Current knowledge of the structure and quantitative relationships of these substances in normal serum is insufficient to permit evaluation of this observation. It could merely be a reflection of the limitations of the methods used for their estimation. However, the fact that the polysaccharides in serum appear to be combined with protein, raises the question of the importance of changes in serum protein patterns to alterations of polysaccharide concentrations. It is known that the glycoproteins of normal serum are not homogeneous substances (18). The various fractions of normal serum protein bind different amounts of polysaccharides. Serum protein patterns may be altered differentially in various diseases, and the distribution of carbohydrates among the serum protein fractions may vary not only from that in normal serum, but also differentially with the disease (27). The sera of patients with diabetic glomerulosclerosis, analyzed by electrophoresis, contain increased concentrations of alpha- 2 globulin and normal amounts of alpha-1 globulin (28). The elevated levels of protein-bound polysaccharides in the sera of our complicated diabetic patients with proven diabetic glomerulosclerosis would appear to be in keeping with the fact that, of the protein fractions in normal serum, alpha-2 globulin contains the highest percentage of polysaccharide (7). The normal amounts of serum mucoprotein in most of our diabetic patients correspond with current evidence that mucoprotein of the serum is a component of alpha- 1 globulin (29). However, in patients with cancer and far advanced tuberculosis, actual values for serum polysaccharides could not be correlated with values calculated from concomitant increases in alpha-2 globulin measured by electrophoresis, and the polysaccharide content of protein fractions isolated from normal serum (30). Moreover, despite the fact that electrophoretic patterns of their sera are normal or characterized by a slight increase in beta globulins (28), hypertensive diabetic patients who do not have diabetic glomerulo- sclerosis, and arteriosclerotic diabetic patients without hypertension, have elevations of their serum polysaccharides of a type and degree comparable to that in patients with a fully developed Kimmelstiel-Wilson's syndrome. Without additional data, it cannot be stated whether the alterations in serum polysaccharides of diabetic patients with degenerative vascular disease reflect changes in the serum protein pattern, in the amounts of carbohydrate in normal protein components, or the appearance of abnormal circulating glycoproteins. In this regard, the variability of the carbohydrate to protein (tyrosine) ratio of the mucoprotein in some diabetic and non-diabetic patients with renal disease, as opposed to its relative constancy in the other groups, is of interest.

We observed a lack of correlation between the levels of the blood sugar and those of the various polysaccharide components which were measured. Our results thus fail to confirm a previous report (4) that there is a remarkable parallelism between blood sugar levels and glucosamine levels. This discrepancy may reflect differences in methods used to estimate glucosamine.

\section{SUM MARY}

1. The concentrations of total non-glucosamine polysaccharides bound to serum protein, serum glucosamine, and the protein (tyrosine) and polysaccharide of serum mucoprotein are within normal limits in diabetic patients without clinically detectable degenerative vascular disease.

2. In diabetic patients with degenerative vascular disease the total polysaccharides bound to serum proteins, and glucosamine of the serum, are increased. The values in such patients are not significantly influenced by the presence of renal involvement. While the mean values remain approximately normal, variations of the carbohydrate to protein ratio of the mucoprotein are found among complicated diabetic patients with proteinuria, renal insufficiency and hypertension. In contrast, this ratio is normal and relatively constant in such patients without renal abnormalities.

3. A uniform relationship between blood sugar levels and the various serum polysaccharide substances measured is not found.

4. The significance of these observations is discussed. 


\section{ACKNOWLEDGMENTS}

We wish to express our appreciation to Dr. Louis Leiter, Chief, Medical Division, and Dr. Harry M. Zimmerman, Chief, Laboratory Division, Montefiore Hospital, for their encouragement and guidance in the planning of this study, and for criticism of the manuscript. We are particularly indebted to Dr. Henry Dolger, Chief of the Diabetic Clinic of The Mt. Sinai Hospital, New York, for his help in obtaining blood samples and generously allowing us access to his clinical records. We would like to thank Miss Ann Solomon for her technical assistance and Mr. Antol Herskovitz for reproducing the text figures.

\section{REFERENCES}

1. McManus, J. F. A., Development of intercapillary glomerulosclerosis. Proc. Am. Diabetes A., 1949, 9, 303.

2. Friedenwald, J. S., Diabetic retinopathy. The fourth Francis I. Porter lecture. Am. J. Ophth., 1950, 33, 1187.

3. Root, H. F., Degenerative complications of diabetes. A review. J. Clin. Endocrinol. \& Metab., 1952, 12, 458.

4. Jacobs, H. R., The bound glucosamine of serum mucoid in diabetes mellitus; fluctuations observed under the influence of insulin. J. Lab. \& Clin. Med., 1949, 34, 116.

5. Shetlar, M. R., Foster, J. V., Kelly, K. H., Shetlar, C. L., Bryan, R. S., and Everett, M. R., The serum polysaccharide level in malignancy and in other pathological conditions. Cancer Research, 1949, 9, 515.

6. West, R., and Clarke, D. H., The concentration of glucosamine in normal and pathological sera. $J$. Clin. Invest., 1938, 17, 173.

7. Seibert, F. B., Seibert, M. V., Atno, A. J., and Campbell, H. W., Variation in protein and polysaccharide content of sera in the chronic diseases, tuberculosis, sarcoidosis and carcinoma. J. Clin. Invest., 1947, 26, 90.

8. Winzler, R. J., and Smyth, I. M., Studies on the mucoprotein of human plasma. II. Plasma mucoprotein levels in cancer patients. J. Clin. Invest., 1948, $27,617$.

9. Simkin, B., Bergman, H. C., and Prinzmetal, M., Studies on coronary circulation. V. Quantitative changes in a serum mucoprotein following the occurrence of myocardial infarction. Am. J. Med., 1949, 6, 734.

10. Israel, H. L., Webster, M. B., and Maher, I. E., Clinical value of serum polysaccharide determinations by the tryptophane-perchloric acid reaction. Am. J. Med., 1949, 6, 745.
11. Kelly, V. C., Good, R. A., and McQuarrie, I., Serum mucoproteins in children in health and disease with special reference to rheumatic fever. Pediatrics, 1950, 5, 824.

12. Kelley, V. C., Good, R. A., and Glick, D., Mucolytic enzyme systems. XI. Hyaluronidase inhibitor and serum mucoproteins in patients with lipoid nephrosis and acute glomerulonephritis. J. Clin. Invest., 1950, 29, 1500.

13. Greenspan, E. M., Lehman, I., Graff, M. M., and Schoenbach, E. B., A comparative study of the serum glycoproteins in patients with parenchymatous hepatic disease or metastatic neoplasia. Cancer, 1951, 4, 972.

14. Rosenberg, C., and Schloss, B., Plasma hexosamine levels in acute rheumatic fever. Am. Heart J., 1949, 38, 872.

15. Rifkin, H., Leiter, L., and Berkman, J., Diabetic glomerulosclerosis. The specific renal disease of diabetes mellitus. Am. Lecture Series No. 130. Chas. C Thomas, Springfield, Ill., 1952.

16. Graff, M. M., Greenspan, E. M., Lehman, I. R., and Holecheck, J. J., Estimation of nonglucosamine polysaccharides of the serum proteins with the anthrone reagent. J. Lab. \& Clin. Med., 1951, $37,736$.

17. Winzler, R. J., Devor, A. W., Mehl, J. W., and Smyth, I. M., Studies on the mucoproteins of human plasma. I. Determination and isolation. J. Clin. Invest., 1948, 27, 609.

18. Meyer, K., Mucoids and glycoproteins, in Advances in Protein Chemistry, Vol. 2. The Academic Press, N. Y., 1945, p. 249.

19. Schlamowitz, S. T., DeGraff, A. C., and Schubert, M., Studies of tissue response to injections of enzymes. II. Changes in rabbit plasma and tissue hexosamine induced by a single subcutaneous injection of trypsin. Circulation, 1950, 1, 822.

20. Catchpole, H. R., Serum and tissue glycoproteins in mice bearing transplantable tumors. Proc. Soc. Exper. Biol. \& Med., 1950, 75, 221.

21. Pirani, C. L., and Catchpole, H. R., Serum glycoproteins in experimental scurvy. Arch. Path., 1951, 51, 597.

22. Engel, M. B., Mobilization of mucoprotein by parathyroid extract. Arch. Path., 1952, 53, 339.

23. Faber, M., The human aorta : sulfate-containing polyuronides and the deposition of cholesterol. Arch. Path., 1949, 48, 342.

24. Altshuler, C. H., and Angevine, D. M., Acid mucopolysaccharide in degenerative disease of connective tissue, with special reference to serous inflammation. Am. J. Path., 1951, 27, 141.

25. Moon, H. D., and Rinehart, J. F., Histogenesis of coronary arteriosclerosis. Circulation, 1952, 6, 481. 
26. Rifkin, H., Berkman, J., Burack, B., and Brodoff, B., Unpublished observations.

27. Shetlar, M. R., Shetlar, C. L., Richmond, V., and Everett, M. R., The polysaccharide content of serum fractions in carcinoma, arthritis, and infections. Cancer Research, 1950, 10, 681.

28. Rifkin, H., and Petermann, M. L., Serum and urinary proteins in diabetic glomerulosclerosis. Results of electrophoretic analysis. Diabetes, 1952, 1, 28.
29. Greenspan, E. M., Tepper, B., Terry, L. T., and Schoenbach, E. B., The serum mucoproteins as an aid in the differentiation of neoplastic from primary parenchymatous liver disease. J. Lab. \& Clin. Med., 1952, 39, 44.

30. Seibert, F. B., Pfaff, M. L., and Seibert, M. V., A serum polysaccharide in tuberculosis and carcinoma. Arch. Biochem., 1948, 18, 279. 